\title{
ATP Mediates Fast Synaptic Potentials in Enteric Neurons
}

\author{
James J. Galligan and Paul P. Bertrand \\ Department of Pharmacology and Toxicology, Michigan State University, East Lansing, Michigan 48824
}

\begin{abstract}
Conventional intracellular electrophysiological methods were used to study fast synaptic transmission in the myenteric plexus of guinea pig ileum in vitro. Fast excitatory postsynaptic potentials (fEPSPs) were evoked in 98 neurons following single stimuli applied to interganglionic connectives. The nicotinic antagonist hexamethonium $(100 \mu \mathrm{M})$ reduced fEPSPs by $83 \%$ in 37 neurons; these fEPSPs were considered to be cholinergic. In 61 neurons, hexamethonium reduced fEPSPs by $33 \%$; fEPSPs recorded in the presence of hexamethonium were considered to be noncholinergic. Similar data were obtained using the nicotinic antagonist mecamylamine (10 $\mu \mathrm{M})$ to block fEPSPs. Hexamethonium or mecamylamine completely blocked depolarizations caused by acetylcholine (ACh) applied by ionophoresis. The $P_{2}$ receptor antagonist suramin (1-300 $\mu \mathrm{m}$ ) inhibited noncholinergic fEPSPs in 30 cells; the suramin $I_{50}$ was $4 \mu \mathrm{M}$. Suramin $(100 \mu \mathrm{M})$ did not block depolarizations caused by ACh or 5-HT, but suramin blocked depolarizations caused by ATP. Hexamethonium did not block ATP-Induced depolarizations. The estimated reversal potential for suramin-sensitive fEPSPs and ATP. induced depolarizations was -25 and $-16 \mathrm{mV}$, respectively. ATP responses were reduced in low-sodium (26 $\mathrm{mm}$ ) extracellular solution, suggesting that ATP activates a cation channel. These data indicate that in myenteric nerves ATP, in addition to $\mathrm{ACh}$, contributes to fast synaptic transmission.

IKey words: enteric nerves, synaptic transmission, purine receptors, ligand-gated ion channels, autonomic nervous system, gastrointestinal tract]
\end{abstract}

ATP is a cotransmitter released with norepinephrine from sympathetic nerves that mediate contractions of some smooth muscle (Burnstock and Kennedy, 1986; von Kugelgen and Starke, 1991). ATP is an agonist at $P_{2}$ purine receptors (Burnstock and Kennedy, 1985) and in smooth muscle cells, ATP acts on $\mathbf{P}_{2}$ receptors to cause depolarization and contraction (Benham et al., 1987; Friel, 1988). Some $\mathrm{P}_{2}$ receptors are likely to be ligandgated cation channels, as they are permeable to sodium, potassium, and calcium and mediate short-latency, short-duration responses (Benham et al., 1987; Friel, 1988). ATP also acts at $\mathrm{P}_{2}$ receptors on sensory neurons (Krishtal et al., 1988; Bean, 1990), autonomic neurons (Allen and Burnstock, 1990; Fieber and Adams, 1991b; Nakazawa, 1994), and neurons in the CNS

\footnotetext{
Received Mar. 25, 1994; revised May 23, 1994; accepted June 1, 1994.

This work was supported by Grants DK40210 and NS01738 from NIH. We thank John Beecher, Drug Services, Center for Disease Control, Atlanta, GA, for the gift of suramin.

Correspondence should be addressed to Dr. James J. Galligan, Department of Pharmacology and Toxicology, Life Sciences Building B440, Michigan State University, East Lansing, MI 48824.

Copyright (C) 1994 Society for Neuroscience $0270-6474 / 94 / 147563-09 \$ 05.00 / 0$
}

(Jahr and Jessell, 1983; Ueno et al., 1992; Shen and North, 1993) to cause responses similar to those caused by acetylcholine (ACh) acting at nicotinic receptors. ATP-activated ion channels are present in cell-free membrane patches from neurons, indicating a close coupling between the ATP binding site and the cation channel (Krishtal et al., 1988; Bean et al., 1990; Silinsky and Gerzanich, 1993). Fast excitatory postsynaptic potentials (fEPSPs), mediated by ATP acting at $\mathrm{P}_{2}$ receptors, have been recorded from guinea pig celiac ganglion neurons (Evans et al., 1992; Silinsky et al., 1992) and from neurons in the medial habenula of the rat (Edwards et al., 1992).

The enteric nervous system (ENS) is the division of the autonomic nervous system residing in the wall of the gastrointestinal tract (Langley, 1921). The ENS is composed of many neurochemically and functionally different neurons that contain a variety of potential neurotransmitters and express receptors for these substances (Furness and Costa, 1987; Wood, 1989). ACh, acting at nicotinic receptors, is the principal excitatory neurotransmitter in the gut and $\mathrm{ACh}$ is believed to be the sole mediator of enteric fEPSPs (Wood, 1989). However, there are other substances contained in the ENS that cause responses similar to nicotinic responses. 5-Hydroxytryptamine (5-HT), acting at $5-\mathrm{HT}_{3}$ receptors, causes short-latency, short-duration depolarizations that are due to an increase in a cation conductance (Mawe et al., 1986; Surprenant and Crist, 1988) and 5-HTactivated channels are present in cell-free patches of enteric neurons (Derkach et al., 1989). In the ENS, ATP also causes fast inward currents and activates cation channels in cell-frec patches of enteric nerves (Bertrand and Galligan, 1992; BarajasLopez et al., 1993, 1994). Although receptors mediating responses similar to nicotinic responses are present in the ENS, enteric noncholinergic fEPSPs have not been identified (Evans and Surprenant, 1992).

In the present study, conventional electrophysiological methods were used to record fEPSPs from myenteric neurons of guinea pig ileum in vitro. Acutely isolated preparations of myenteric plexus were used, as most synaptic connections present in the intact intestine are preserved. We have shown that ATP mimics fEPSPs and that the $P_{2}$ receptor antagonist suramin (Dunn and Blakely, 1988; Hoyle et al., 1990) blocks some fEPSPs. We conclude that ATP is a mediator of noncholinergic fEPSPs in the ENS.

\section{Materials and Methods}

Tissue preparation. Male guinea pigs weighing 250-350 gm were anesthetized via halothane inhalation, stunned, and bled through the neck. A segment of ileum was excised $10-20 \mathrm{~cm}$ proximal to the ileocecal junction and placed in oxygenated $\left(95 \% \mathrm{O}_{2} / 5 \% \mathrm{CO}_{2}\right)$ Krebs solution of the following composition (millimolar): $\mathrm{NaCl}, 117 ; \mathrm{KCl}, 4.7 ; \mathrm{CaCl}_{2}, 2.5$; $\mathrm{MgCl}_{2}, 1.2 ; \mathrm{NaHCO}_{3}, 25 ; \mathrm{NaH}_{2} \mathrm{PO}_{4}, 1.2$; glucose, 11 . The Krebs solution contained nifedipine $(1 \mu \mathrm{M})$ and scopolamine $(1 \mu \mathrm{M})$ to block 
longitudinal muscle contractions and muscarinic receptors on myenteric nerves during intracellular recordings. A $1.5 \mathrm{~cm}$ segment of ileum was cut open along the mesenteric border and pinned out flat (mucosal surface up) in a pctri dish lincd with Silastic clastomer. A longitudinal muscle-myenteric plexus preparation was made by stripping away the mucosal, submucosal, and circular muscle layers using fine forceps and scissors. A $5 \mathrm{~mm}^{2}$ piece of longitudinal muscle myenteric plexus was transferred to a small recording chamber ( $2 \mathrm{ml}$ volume) lined with Silastic elastomer. The preparation was stretched lightly and pinned to the chamber bottom using small stainless steel pins. The preparation was superfused with $36^{\circ} \mathrm{C}$, oxygenated Krebs solution at a flow rate of $7 \mathrm{ml} / \mathrm{min}$.

Intracellular recording. Individual myenteric ganglia were visualized at $200 \times$ magnification using an inverted microscope (Nikon Diaphot or Olympus CK-2) with differential interference contrast optics (Hoffman Modulation). Intracellular recordings were obtained from single neurons using glass microelectrodes filled with $2 \mathrm{M} \mathrm{KCl}$ (tip resistance, 80-120 M 2 ). An amplifier with an active bridge circuit (Axoclamp 2A, Axon Instruments, Foster City, CA) was used for membrane potential recordings and for injection of current into neurons via the recording microelectrode. In most experiments, the membrane potential was adjusted to a potential negative to $-70 \mathrm{mV}$ using constant DC current to avoid action potentials when evoking fEPSPs. Signals were filtered at $1 \mathrm{kHz}$ using a 4-pole Bessel filter (Warner Instruments, New Haven, CT), digitized at $1 \mathrm{kHz}$ using a Labmaster TL- 1 or Digitdata 1200 analog/digital converter (both from Axon Instruments) and acquired and stored using AXOTAPE 2.0 (Axon Instruments) and a personal computer.

Synaptic potentials were evoked using a broken-back glass pipette (tip diameter 40-60 $\mu \mathrm{M}$ ) filled with Krebs solution as a focal stimulating electrode. The stimulating electrode was positioned on an interganglionic ncrve strand. To cvoke an fEPSP, nerve fibcrs were stimulated using single stimuli of $0.3 \mathrm{msec}$ duration applied at a rate of $0.2 \mathrm{~Hz}$. When studying fEPSPs, 6-12 individual responses were averaged. In some experiments, slow excitatory postsynaptic potentials (sEPSPs) were evoked using trains of stimuli ( $20 \mathrm{~Hz}$ for $500 \mathrm{msec})$. The amplitude of single sEPSPs before and after drug treatment was measured.

Drug application. Antagonists were applied by superfusion in a known concentration by addition to the superfusing Krebs solution. Antagonists were applied for 4-12 min prior to measuring the amplitude of the evoked response. When constructing antagonist concentration-response curves, successive antagonist concentrations were applied cumulatively and each concentration was present for a minimum of $4 \mathrm{~min}$ before measuring the amplitude of the evoked response. ACh was applied by ionophoresis from an electrode (tip resistance $<20 \mathrm{M} \Omega$ ) placed dircetly above the impalcd neuron. The concentration of $\mathrm{ACh}$ in the electrode was $1 \mathrm{M}$. A retaining current of $-6 \mathrm{nA}$ was used and cathodal current pulses of 1-20 msec duration and 100-199 $\mathrm{nA}$ intensity were used. An average of 6-12 individual ACh responses was obtained for each treatment. ATP was applied by pressure ejection (10 psi) from a fine-tipped $(<10 \mu \mathrm{m}$ ) pipette positioned within $200 \mu \mathrm{m}$ of the impaled neuron. The concentration of ATP in the pipette was 100 or $300 \mu \mathrm{M}$.

Statistics. All data are expressed as the mean \pm SEM. Student's $t$ test for paired data or analysis of variance were used to establish significant differences between control and treatment groups. Antagonist inhibition of EPSPs, ACh, or ATP responses is expressed as percentage change from control amplitude. Concentration-response curves were plotted and concentrations of antagonist causing half-maximal inhibition $\left(\mathrm{IC}_{50}\right)$ were determined from average concentration-response curves.

Drugs. Mccamylaminc was obtained from Research Biochemicals Inc. (Natick, MA). Suramin was a gift from the Center for Disease Control (Atlanta, GA). All other drugs and chemicals were obtained from Sigma Chemical Co. (St. Louis, MO).

\section{Results}

Nicotinic receptor antagonists, but not suramin, block

ACh-induced depolarizations

ACh was applied by ionophoresis to cause a depolarization that was similar in amplitude and time course to fEPSPs recorded from myenteric neurons (Fig. 1A). Hexamethonium inhibited ACh-induced depolarizations in a concentration-dependent manner and the $\mathrm{ACh}$ response was completely blocked by 100 $\mu \mathrm{M}$ hexamethonium (Fig. $1 A, B$ ). The $\mathrm{IC}_{50}$ for hexamethonium was $3 \mu \mathrm{M}$ at a membrane potential of $-88 \pm 5 \mathrm{mV}(n=9)$. Similar experiments were done using the nicotinic antagonist mecamylamine, which also inhibited ACh-induced depolarizations in a concentration-dependent manner (Fig. $1 B$ ). Mecamylamine $(10 \mu \mathrm{M})$ completely blocked the ACh response and the mecamylamine $\mathrm{IC}_{50}$ was $0.12 \mu \mathrm{M}$ at a membrane potential of $-88 \pm 6 \mathrm{mV}(n=7)$. These data indicate that hexamethonium and mecamylamine can completcly block nicotinic receptors activated by $\mathrm{ACh}$ when it is applied in a manner that mimics the amplitude and duration of fEPSPs.

ACh was applied by ionophoresis in the absence and presence of the $\mathrm{P}_{2}$ receptor antagonist suramin (Fig. 2A). Suramin did not change the amplitude of the $\mathrm{ACh}$ response in any neuron tested (Fig. 2B). Furthermore, suramin $(100 \mu \mathrm{M})$ did not block depolarizations caused by 5 -HT (control, $23 \pm 1 \mathrm{mV}$; suramin, $23 \pm 5 \mathrm{mV} ; n=2$ ). The 5 -HT depolarizations were blocked by the $5-\mathrm{HT}_{3}$ receptor antagonist ondansetron $(1 \mu \mathrm{M})$ (control, 26 $\pm 4 \mathrm{mV}$; ondansetron, $6 \pm 4 \mathrm{mV} ; n=3, p<0.01$ ).

\section{Noncholinergic fEPSPS in myenteric neurons}

Single electrical stimuli applied to interganglionic nerve strands evoked an fEPSP in 98 neurons; the average amplitude of the fEPSP was $23 \pm 4 \mathrm{mV}$. None of these neurons exhibited a spike afterhyperpolarization that lasted longer than $1 \mathrm{sec}$, and these cells would be classified as " $S$ " neurons according to the criteria of Hirst et al. (1974). Hexamethonium $(100 \mu \mathrm{M})$ reduced the fEPSP by $83 \pm 1 \%$ in 37 neurons; in the presence of hexamethonium the fEPSP was $4 \pm 0.4 \mathrm{mV}$ at a membrane potential of $-90 \pm 4 \mathrm{mV}$ (Fig. $3 A$, left). These fEPSPs were considered to be cholinergic. In 61 neurons, hexamethonium $(100 \mu \mathrm{M})$ reduced the fEPSP by $34 \pm 3 \%$; in these cells, fEPSP amplitude was $15 \pm 1 \mathrm{mV}$ in the presence of the antagonist at a membrane potential of $-97 \pm 3 \mathrm{mV}$. Hexamethonium-resistant fEPSPs were completely blocked by tetrodotoxin $(0.3 \mu \mathrm{M}, n=9)$ (Fig. $3 A$, right). The control distribution of fEPSP amplitude was dispersed over a range of amplitudes between 10 and $40 \mathrm{mV}$ (Fig. $3 B$ ). The distribution of fEPSP amplitudes in the presence of hexamethonium was skewed towards smaller amplitudes with a peak at less than $10 \mathrm{mV}$ (Fig. 3C). There was a large overlap of the two distributions indicating that most fEPSPs in the myenteric plexus are a mixture of hexamethonium-sensitive and -insensitive components.

Although it was shown above that $100 \mu \mathrm{M}$ hexamethonium completely blocked responses to $\mathrm{ACh}$, it is possible that iontophoretically applied ACh and neurally released $\mathrm{ACh}$ act at different sites and that higher concentrations of hexamethonium may required to block nicotinic fEPSPs. This differential sensitivity of receptors could account for the occurrence of hexamethonium- resistant fEPSPs. This possibility was tested in two ways. First, in 12 neurons in which the fEPSP was partly reduced by $100 \mu \mathrm{M}$ hexamethonium, it was found that a higher concentration of hexamethonium $(300 \mu \mathrm{M})$ did not further reduce the fEPSP (Fig. 4A,B). Second, mecamylamine was also used to determine if some fEPSPs recorded from myenteric neurons were noncholinergic. In 4 of 11 neurons, mecamylamine (10 $\mu \mathrm{M}$ ) reduced the fEPSP by $77 \pm 2 \%$ (Fig. $4 C$ ), while in 7 of 11 neurons, mecamylamine reduced the fEPSP by only $32 \pm 9 \%$ (Fig. 4D). Taken together, these data indicate that the failure of $100 \mu \mathrm{M}$ hexamethonium to block completely the fEPSP in some neurons cannot be attributed to the use of an insufficient concentration of antagonist or to a population of hexamethoniumresistant nicotinic receptors. Instead, the fEPSP in most myen- 


\section{ACh ionophoresis}

A

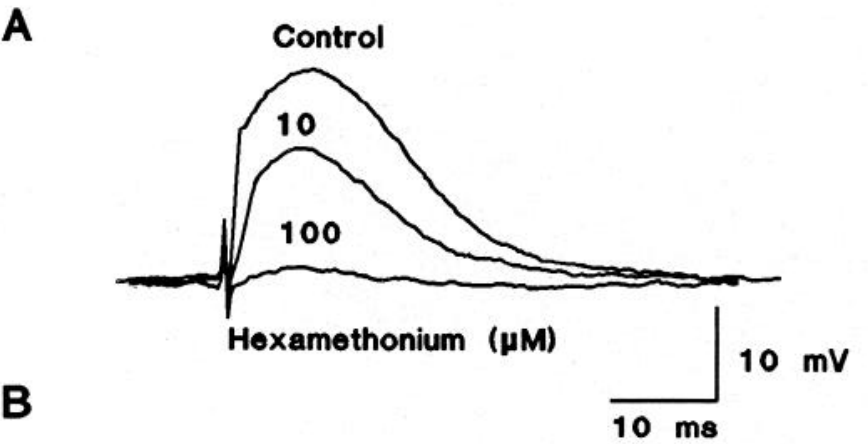

B

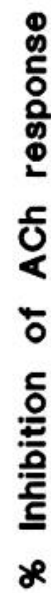

Mecamylamine

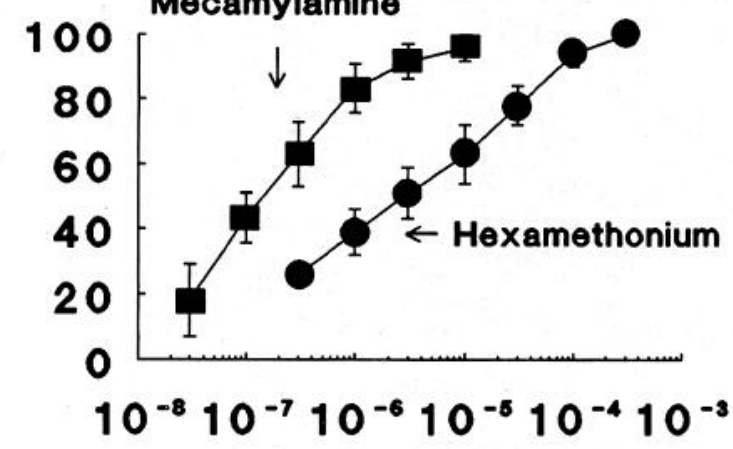

[Antagonist](M)

Figure 1. Nicotinic receptor antagonists block ACh-induced depolarizations of myenteric neurons. A, ACh applied by ionophoresis $(2 \mathrm{msec}$, $100 \mathrm{nA}$ ) to a myenteric neuron causes a depolarization that is inhibited by 10 and $100 \mu \mathrm{m}$ hexamethonium. $B$, Concentration-response curves for inhibition of $\mathrm{ACh}$-induced depolarizations by hexamethonium and mecamylamine. Data obtained from experiments similar to that shown in $A$ and are the mean \pm SEM of three to nine cells per point.

teric neurons is due to the action of a neurotransmitter or neurotransmitters in addition to $\mathrm{ACh}$ and the hexamethoniumresistant fEPSP is a noncholinergic synaptic event. The data presented in Table 1 show that the latency, time to peak, and time to half-decay for noncholinergic fEPSPs were similar to the time course of nicotinic fEPSPs.

Noncholinergic fEPSPs blocked by the $P_{2}$ receptor antagonist suramin

Suramin $(100 \mu \mathrm{M})$ was applied to 35 of 61 neurons in which the fEPSP was partly reduced by hexamethonium $(100 \mu \mathrm{M})$. In five

\section{ACh response}

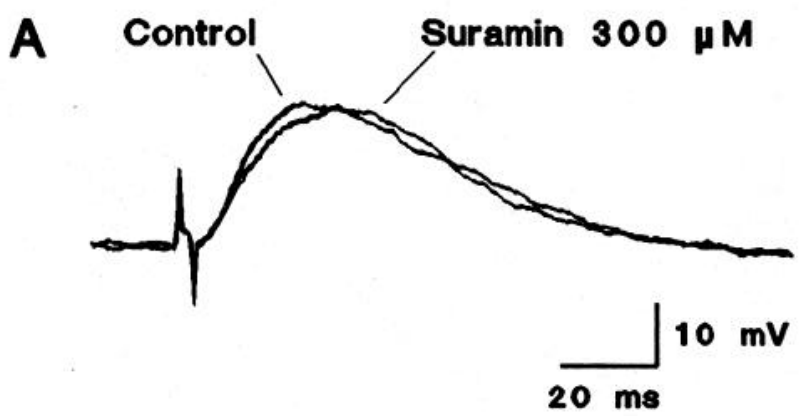

B

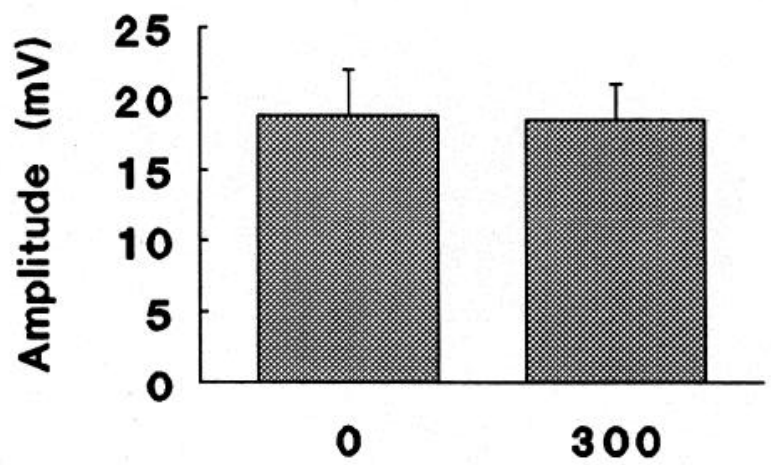

[Suramin]( $\mu \mathrm{M})$

Figure 2. Suramin does not alter ACh-induced depolarizations. A, ACh applied by ionophoresis $(5 \mathrm{msec}, 199 \mathrm{nA})$ causes a depolarization that is not reduced in amplitude by suramin. $B$, Data from experiments similar to $A$ demonstrating that suramin $(300 \mu \mathrm{M})$ does not inhibit $\mathrm{ACh}$ responses in myenteric neurons $(n=6)$.

cells, suramin reduced the noncholinergic fEPSP by less than $20 \%$. In 30 cells, suramin $(100 \mu \mathrm{M})$ reduced the noncholinergic fEPSP by $71 \pm 4 \%$ (Fig. $5 A$ ). The control noncholinergic fEPSP was $17 \pm 1 \mathrm{mV}$, and in the presence of suramin the fEPSP was $5 \pm 1 \mathrm{mV}(p<0.01)$. Inhibition of the noncholinergic fEPSP by suramin was concentration dependent; the suramin $\mathrm{IC}_{50}$ was $4 \mu \mathrm{M}$ (Fig. $5 B$ ). Although it was shown above that suramin did not block responses to ACh or 5-HT, it is possible that suramin could act nonspecifically to disrupt synaptic transmission. This possibility is unlikely because there were some noncholinergic fEPSPs that were unaffected by suramin and it was also found that suramin $(100 \mu \mathrm{M})$ did not change the amplitude of sEPSPs elicited by brief trains of stimuli (control sEPSP, $22 \pm 4 \mathrm{mV}$; sEPSP in the presence of suramin, $17 \pm 3 \mathrm{mV} ; n=5, p>0.05$ ).

Table 1. Time course of cholinergic and noncholinergic fEPSPs in myenteric neurons

\begin{tabular}{lllll} 
& Latency $(\mathrm{msec})$ & $\begin{array}{l}\text { Time to peak } \\
(\mathrm{msec})\end{array}$ & $\begin{array}{l}\text { Half-decay } \\
(\mathrm{msec})\end{array}$ & $\begin{array}{c}\text { Amplitude } \\
(\mathrm{mV})\end{array}$ \\
\hline $\begin{array}{l}\text { Cholinergic fEPSP } \\
(n=11)\end{array}$ & $3.1 \pm 0.4$ & $4.0 \pm 0.6$ & $13.1 \pm 2.5$ & $20.7 \pm 2.5$ \\
$\begin{array}{c}\text { Noncholinergic fEPSP } \\
(n=10)\end{array}$ & $3.5 \pm 0.2$ & $4.1 \pm 0.6$ & $12.3 \pm 1.2$ & $20.6 \pm 1.2$
\end{tabular}


fEPSP
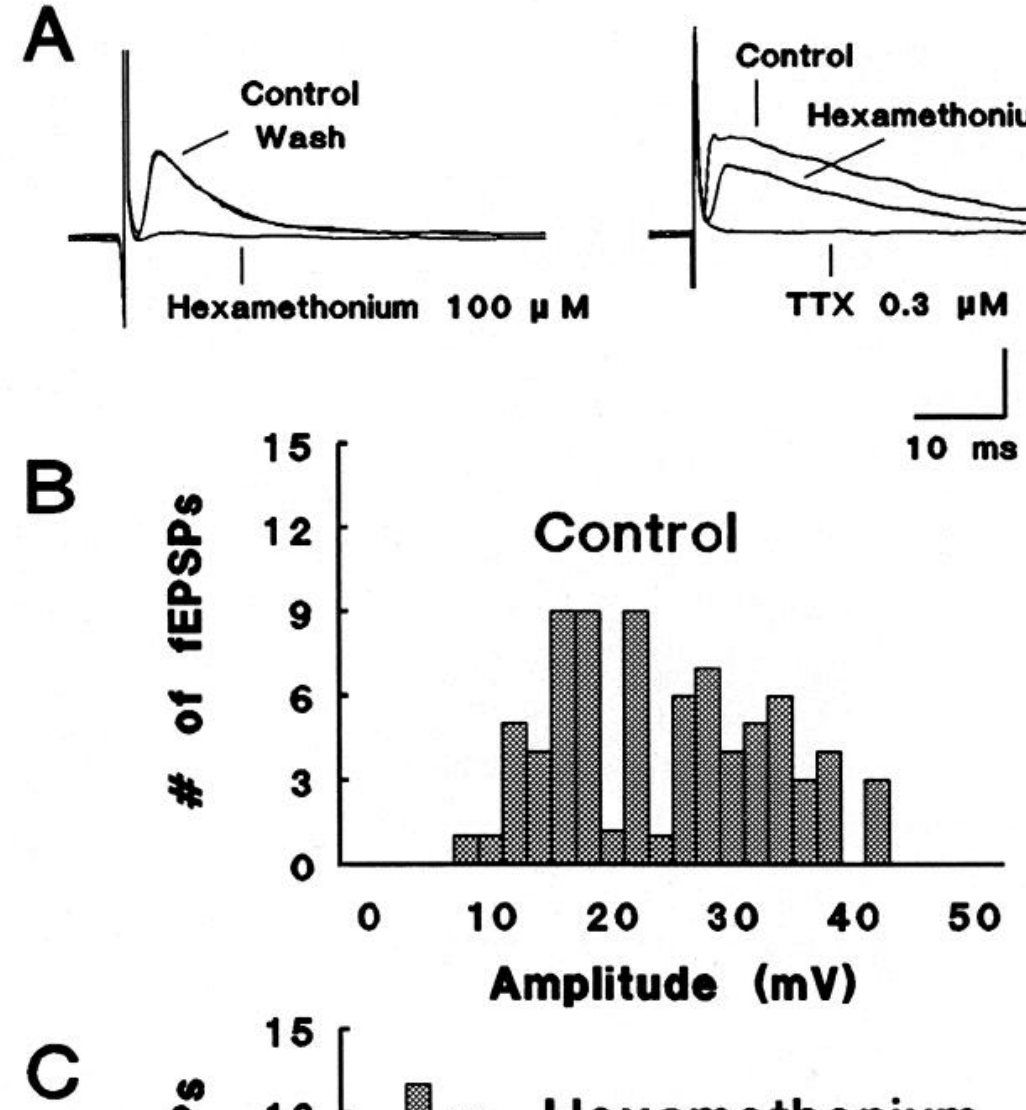

Figure 3. Cholinergic and noncholinergic fEPSPs. A: Left, fEPSP that was completely blocked by hexamethonium. Right, Recording from a different neuron with an fEPSP that was partly reduced in amplitude by hexamethonium. The noncholinergic fEPSP was completely blocked by tetrodotoxin (TTX). B, Amplitude-frequency distribution for fEPSPs recorded in the absence of hexamethonium. $C$, Amplitude-frequency distribution for fEPSPs recorded in the presence of hexamethonium $(100 \mu \mathrm{M})$.

The reversal potential for the noncholinergic fEPSP was determined in experiments similar to that shown in Figure 6, $\mathrm{A}$ and $B$. The amplitude of the suramin-sensitive fEPSP was measured at different membrane potentials in the presence of hexamethonium $(100 \mu \mathrm{M})$. In this cell, the estimated reversal potential was $-15 \mathrm{mV}$ (Fig. $6 C$ ). This experiment was repeated in six additional neurons and the average estimated reversal potential was $-25 \pm 7 \mathrm{mV}$. This value was similar to the estimated reversal potential for fEPSPs measured in the absence of hexamethonium $(-24 \pm 6 \mathrm{mV}, n=8)$.

\section{ATP mimics noncholinergic $f E P S P S$}

ATP was applied by pressure ejection from a micropipette onto neurons exhibiting noncholinergic fEPSPs. ATP caused a depolarization of 1-2 sec duration and the depolarization was

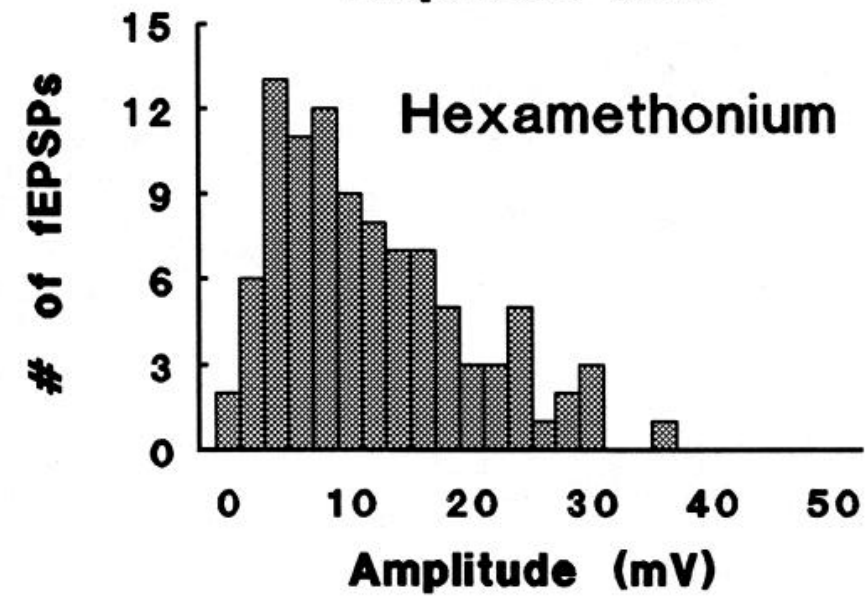
(Fig. 7A), but this response was not studied.

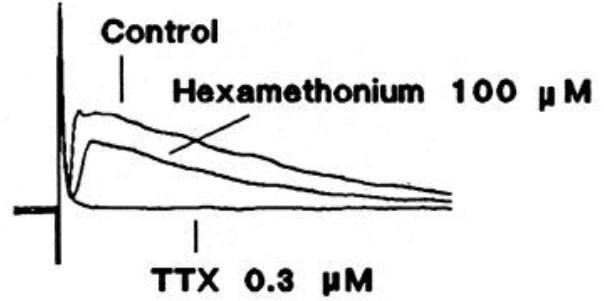

$10 \mathrm{mV}$

associated with a decrease in membrane input resistance (Fig. $7 A)$. In 8 of 10 neurons in which the fEPSP was suramin sensitive, ATP caused a fast depolarization. ATP caused a fast depolarization in only one of eight neurons in which the fEPSP was completely blocked by hexamethonium. The fast depolarization caused by ATP was blocked by suramin $(100 \mu \mathrm{M})$ (Fig. $7 B)$. Hexamethonium $(100 \mu \mathrm{M})$ did not block ATP-induced depolarizations (control, $22 \pm 4 \mathrm{mV}$; hexamethonium, $26 \pm 3$ $\mathrm{mV} ; n=2)$. In some cells, ATP also caused a slow depolarization

The reversal potential for the ATP response was estimated in experiments similar to that shown in Figure 8 where the amplitude of the ATP response was measured at different membrane potentials. In the experiment shown in Figure 8, the estimated reversal potential was $-2 \mathrm{mV}$. Similar experiments 


\section{fEPSP}
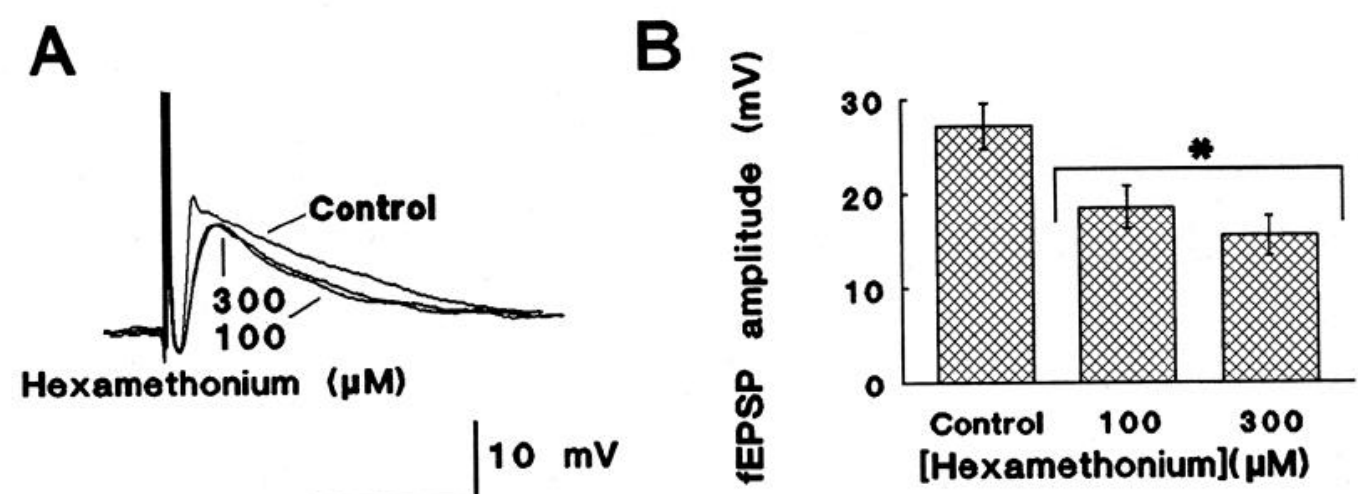

$10 \mathrm{~ms}$
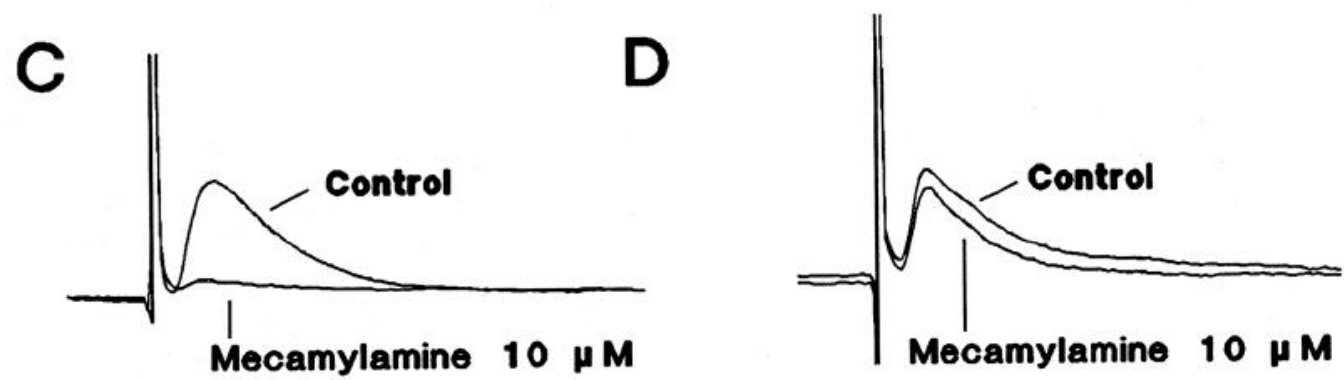

Figure 4. Effects of hexamethonium and mecamylamine on fEPSPs. $A$, fEPSP reduced in amplitude by $100 \mu \mathrm{M}$ hexamethonium and $300 \mu \mathrm{M}$ hexamethonium does not further reduce fEPSP amplitude. $B$, Data from experiments similar to that shown in $A(n=12)$. Hexamethonium at 100 and $300 \mu \mathrm{M}$ significantly reduced the amplitude of the fEPSP $(p<0.05)$ but the effects of $100 \mu \mathrm{M}$ are not different from the effects of $300 \mu \mathrm{M}(p$ $>0.05$ ). Data were analyzed by ANOVA and the least significant difference test.

were repeated in three additional neurons, and the average estimated reversal potential was $-16 \pm 5 \mathrm{mV}$. The decrease in input resistance during the ATP response and the reversal potential near $0 \mathrm{mV}$ suggests that the ATP response in myenteric neurons may be due to an increase in a nonspecific cation conductance. Consistent with this suggestion, it was found that reducing the extracellular sodium concentration from $145 \mathrm{~mm}$ to $26 \mathrm{~mm}$ (choline chloride substitution for sodium chloride) shifted the reversal potential to $-31 \pm 1 \mathrm{mV}(n=3)$ (Fig. $8 B$ ).

\section{Discussion}

Noncholinergic fast synaptic transmission in the myenteric plexus

There are many potential neurotransmitters contained in the ENS (Furness and Costa, 1987). In addition to ACh, these potential neurotransmitters include 5-HT, GABA, nitric oxide, and many neuropeptides. Studies of the contribution of noncholinergic neurotransmitters to synaptic transmission in the ENS have focused on slow synaptic events and it has been assumed that ACh is the sole mediator of fast synaptic transmission between enteric nerves (Wood, 1989). However, in the present study, we have shown that in most myenteric neurons of guinea pig small intestine fEPSPs are mediated by neurotransmitters in addition to ACh acting at nicotinic receptors. This conclusion is based on the observation that most fEPSPs were not completely blocked by the nicotinic antagonist hexamethonium.
The failure of hexamethonium to block the fEPSP was not due to the use of insufficient concentrations of antagonist. ACh was applied by ionophoresis onto neurons, and the ACh response was similar in time course and amplitude to the fEPSP. This observation indicates that ionophoretically applied ACh and neurally released transmitter were acting at similar sites to cause a depolarization. The concentration of hexamethonium $(100 \mu \mathrm{M})$ used to study fEPSPs was 30 -fold higher than its IC $_{s 0}$ value $(3 \mu \mathrm{M})$ determined in studies of the $\mathrm{ACh}$ response, and at a concentration of $100 \mu \mathrm{M}$ hexamethonium completely blocked $\mathrm{ACh}$ responses. In addition, in neurons in which $100 \mu \mathrm{M}$ hexamethonium did not completely block the fEPSP, a higher concentration of hexamethonium $(300 \mu \mathrm{M})$ did not further reduce the amplitude of the fEPSP.

The fEPSPs that were not blocked by hexamethonium were not due to an action of neurally released $\mathrm{ACh}$ at a population of hexamethonium-insensitive nicotinic receptors. Mecamylamine, another antagonist of ganglionic nicotinic receptors (Fieber and Adams, 1991a), was used to determine if some nicotinic receptors in the ENS were resistant to hexamethonium. Mecamylamine was an effective antagonist of $\mathrm{ACh}$ responses, and the concentration of mecamylamine $(10 \mu \mathrm{M})$ used to study fEPSPs was almost 100 -fold higher than the $\mathrm{IC}_{50}$ value $(0.12 \mu \mathrm{M})$ determined for block of the $\mathrm{ACh}$ response. At a concentration 10 $\mu \mathrm{M}$, mecamylamine did not block all fEPSPs recorded from myenteric neurons. In addition, mecamylamine and hexamethonium are open channel blockers of the nicotinic receptor, 


\section{Noncholinergic fEPSP}
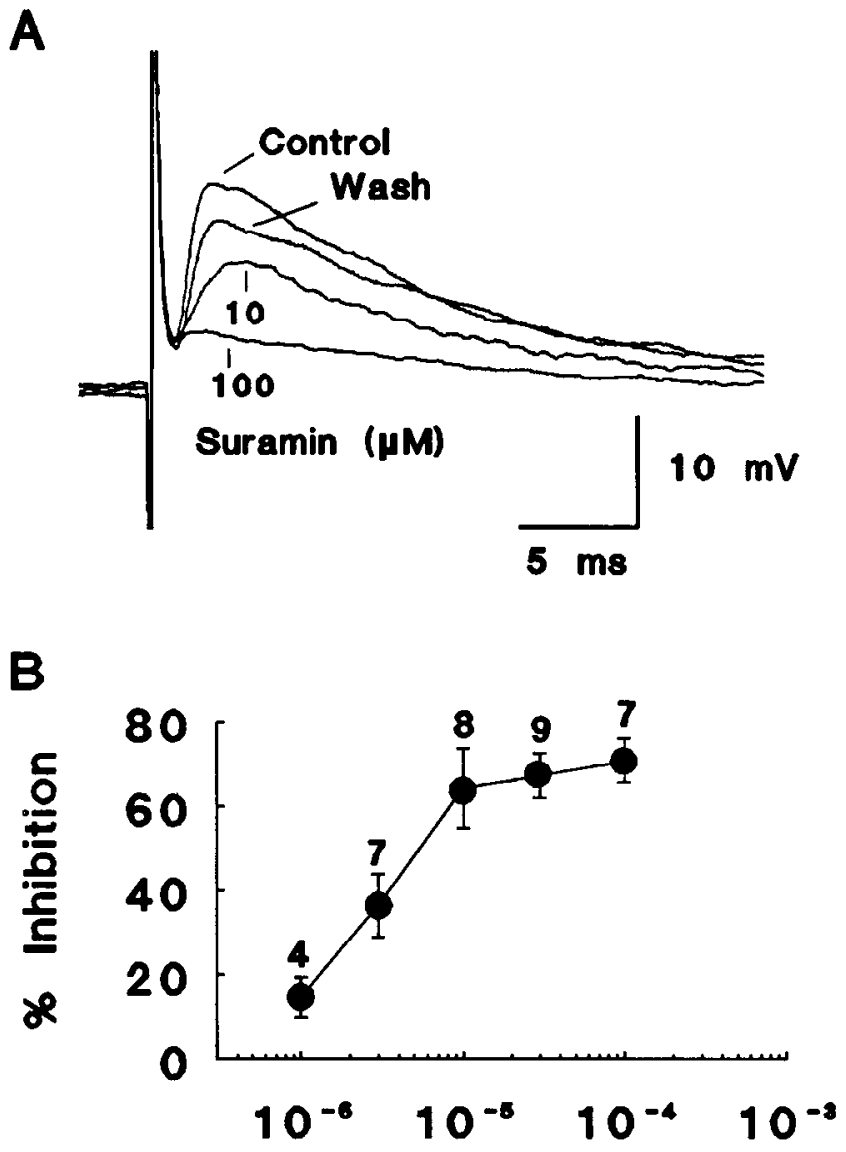

[Suramin](M)

Figure 5. Suramin inhibits noncholinergic fEPSPs. $A$, In the presence of hexamethonium $(100 \mu \mathrm{M})$ suramin at 10 and $100 \mu \mathrm{M}$ reversibly inhibits the noncholinergic fEPSP. Wash indicates recovery from suramin; hexamethonium was present throughout. $B$, Concentration-responses curve for inhibition of noncholinergic fEPSP by suramin. Data are the mean \pm SEM of the indicated number of cells per data point.

and the block caused by these drugs is enhanced at hyperpolarized membrane potentials (Ascher et al., 1979; Fieber and Adams, 1991a). We studied the action of hexamethonium and mecamylamine on fEPSPs at potentials near $-90 \mathrm{mV}$, which would increase the block of the nicotinic receptor produced by these drugs when compared to their effects at potentials near rest $(-60 \mathrm{mV})$. Finally, there was a subpopulation of neurons in which hexamethonium or mecamylamine reduced the fEPSP by more $80 \%$, indicating that some fEPSPs were largely mediated by neurally released ACh acting at nicotinic receptors and that the nicotinic antagonists can block these receptors.

The noncholinergic response was completely blocked by tetrodotoxin, indicating that it was dependent on presynaptic action potentials. The latency, rise time, and decay time of the noncholinergic response were similar to the observed times for fEPSPs that were blocked by the nicotinic receptor antagonists. Therefore, the noncholinergic response is likely to be due to the action of a neurotransmitter at a ligand-gated ion channel similar to the nicotinic receptor. These data indicate that when nicotinic receptors are blocked by hexamethonium or meca- mylamine, the remaining fEPSPs are noncholinergic. The marked overlap of the frequency distributions of fEPSP amplitudes in the absence and presence of hexamethonium indicates that most fEPSPs elicited by electrical stimulation in the ENS are due to the action of a transmitter or transmitters in addition to $\mathrm{ACh}$.

\section{ATP mediates noncholinergic $f E P S P S$}

ATP acts at $\mathbf{P}_{2}$ receptors on smooth muscle cells (Benham et al., 1987; Friel, 1988), sensory neurons (Krishtal et al., 1988; Bean, 1990), autonomic neurons (Fieber and Adams, 1991b; Nakazawa, 1994), and neurons in the CNS (Ueno et al., 1992; Shen and North, 1993) to cause a depolarization or inward current. The short latency, time course, and reversal potential (near $0 \mathrm{mV}$ ) of these responses have led to the conclusion that the purine receptor at which $\Lambda T P$ acts is a ligand-gated cation channel with properties similar to the nicotinic receptor (Bean, 1992). The $P_{2}$ receptor antagonist suramin (Dunn and Blakely 1988; Hoyle et al., 1990) blocks ATP-induced responses in peripheral neurons (Nakazawa, 1994) and PC12 cells (Nakazawa et al., 1991a). Suramin has also been used to show that synaptic responses recorded from medial habenula neurons (Edwards et al., 1992) and neurons from guinea pig celiac ganglion in tissue culture are mediated by ATP (Evans et al., 1992; Silinsky and Gerzanich, 1993). In the present study, suramin reduced noncholinergic fEPSPs in $\mathbf{3 0}$ of $\mathbf{3 5}$ neurons tested. The inhibition of noncholinergic fEPSPs by suramin was concentration dependent and, on average, suramin reduced the noncholinergic component of the fEPSP by a maximum of $70 \%$.

In neurons exhibiting a suramin-sensitive fEPSP, ATP caused a fast depolarization ( $<2 \mathrm{sec}$ duration), and the fast depolarization was associated with a decrease in input resistance. ATP generally did not cause a fast depolarization in neurons in which the fEPSP was blocked by hexamethonium. The depolarization caused by ATP was blocked by suramin but suramin did not block ACh responses or depolarizations caused by $5-\mathrm{HT}$ acting at $5-\mathrm{HT}_{3}$ receptors. Depolarizations caused by $5-\mathrm{HT}$ were blocked by the $5-\mathrm{HT}_{3}$ receptor antagonist ondansetron (Derkach et al., 1989; Vanner and Surprenant, 1990). Suramin did not block noncholinergic fEPSPs via a nonspecific action on synaptic transmission, as some noncholinergic fEPSPs were not blocked by suramin and slow synaptic potentials evoked by trains of stimuli were not affected by suramin.

In other cells, ATP activates a nonspecific cation channel as ATP-induced currents reverse polarity near $0 \mathrm{mV}$ and reducing extracellular sodium shifts the reversal potential in a negative direction (Benham et al., 1987; Friel, 1988; Krishtal et al., 1988; Fieber and Adams, 1991 b; Nakazawa et al., 1991b). As the ATP response recorded from myenteric neurons was associated with a decreased input resistance, the ATP response and noncholinergic fEPSP could be due to activation of a cation conductance. The estimated reversal potential for the noncholinergic fEPSP $(-25 \mathrm{mV})$ and the ATP response $(-16 \mathrm{mV})$ were similar and were not different from that measured for the nicotinic fEPSP (Wood, 1989). These data are consistent with the noncholinergic fEPSP and ATP responses being due to the activation of a nonspecific cation channel similar to the nicotinic receptor. However, our estimates of the ATP reversal potential and the reversal potential of the noncholinergic fEPSP are more negative than those obtained by others for ATP responses and suraminsensitive synaptic responses (Benham et al., 1987; Friel, 1988; Bean et al., 1990; Fieber and Adams, 1991b; Edwards et al., 1992; Evans et al., 1992; Nakazawa, 1994; Silinsky and Ger- 


\section{Noncholinergic fEPSP}

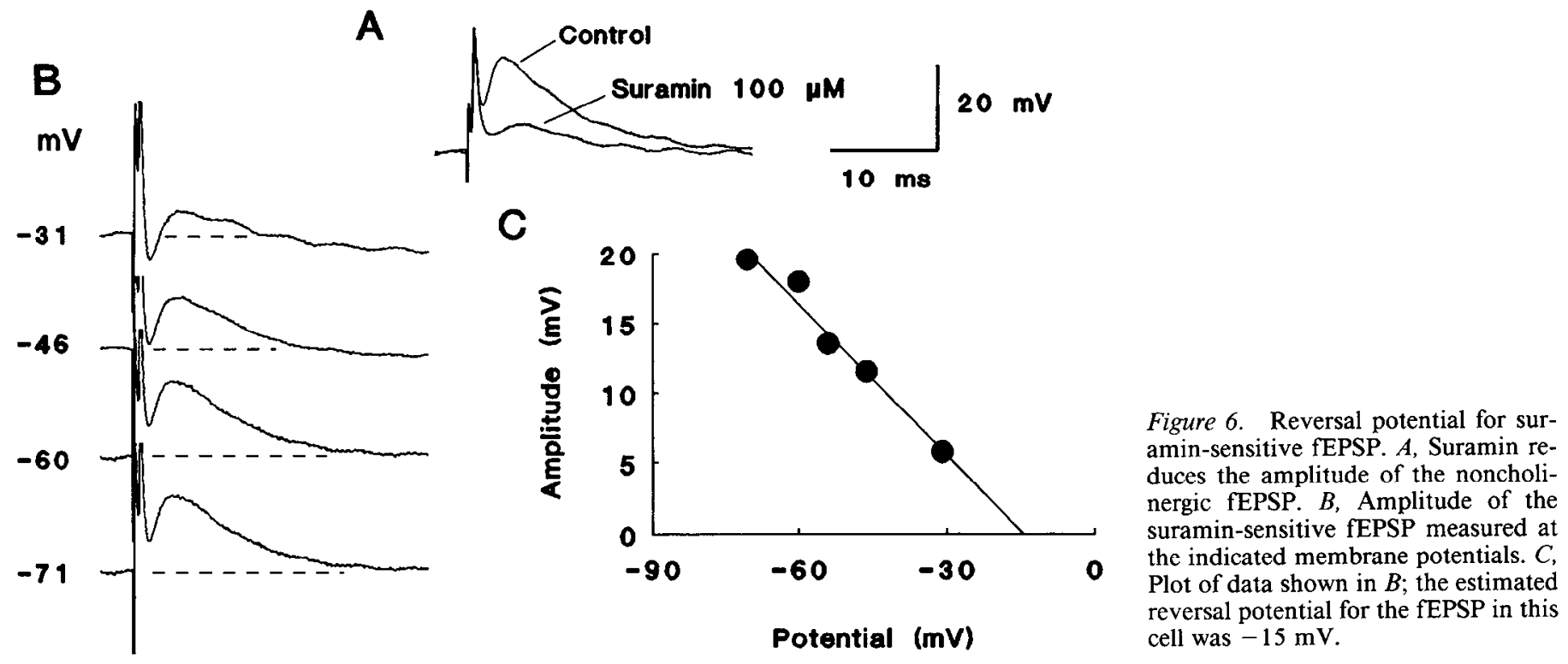

A

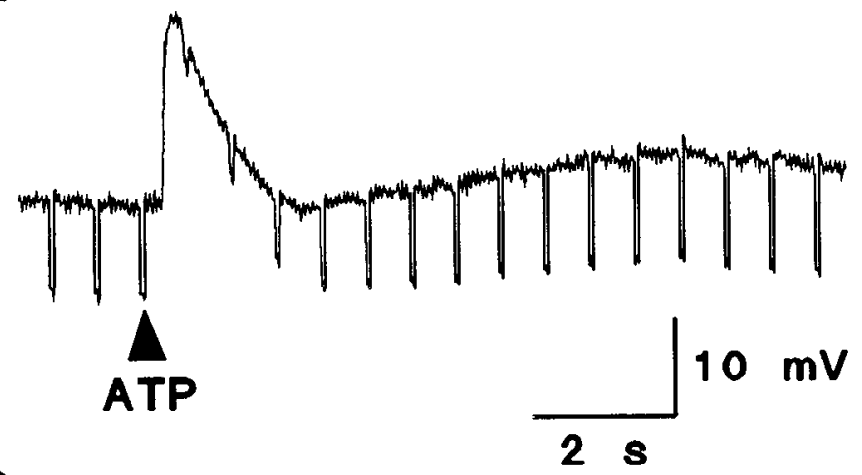

B

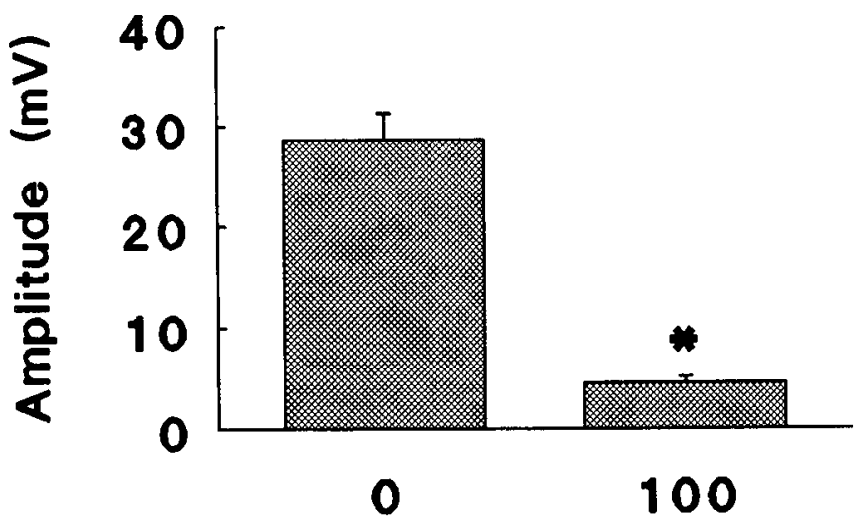

[Suramin]( $\mu \mathrm{M})$

Figure 7. ATP mimics the noncholinergic fEPSP. $A$, Depolarization caused by ATP (triangle) applied by pressure ejection from a micropipette. Downward deflections are voltage responses to $200 \mathrm{pA}, 100$ msec-duration hyperpolarizing current pulses passed through the recording microelectrode. Decrease in amplitude of these voltage re- zanich, 1993). This discrepancy may be due to the inward rectification exhibited by ATP-induced currents and suramin-sensitive fEPSPs. We used high-resistance intracellular microelectrodes (80-120 M $)$. Therefore, the amplitude of noncholinergic fEPSPs and ATP responses could be measured at potentials only as positive as $-20 \mathrm{mV}$, and the reversal potential was estimated by extrapolation. As we did not measure the ATP response or the noncholinergic fEPSP in the range of potentials where ATP currents rectify, it is likely that our estimate of the reversal potential is more negative than the actual reversal potential. Alternatively, the properties of the ATP-activated channel in myenteric neurons may be different from the same channels in other cell types.

The ATP response was reduced when it was studied in low extracellular sodium solutions ( $26 \mathrm{~mm}$ ). In low-sodium solutions, the ATP reversal potential shifted to $-30 \mathrm{mV}$; this shift is less than that would be predicted when reducing the extracellular sodium concentration by $80 \%$. Under thesc conditions, the ATP reversal potential should have shifted in the negative direction by $50 \mathrm{mV}$. The smaller shift measured here could be attributed to the rectifying properties of the ATP-activated channel or the channel in myenteric neurons may be somewhat permeable to choline and other cations including calcium, as shown in other cell types (Benham et al., 1987; Friel, 1988; Fieber and Adams, 1991 b; Nakazawa et al., 1991b; Ueno el al., 1992).

In some neurons, the fast depolarization caused by ATP was followed by a slow depolarization. The slow depolarization caused by ATP in enteric neurons has been shown by others to be due to an inhibition of resting potassium channels (Katayama and Morita, 1989). It remains to be determined if there are slow synaptic potentials in the ENS that are also mediated by ATP.

sponses indicates a decrease in input resistance during the ATP response. $B$, ATP responses are blocked by suramin. Asterisk indicates significantly different from control $(p<0.05, n=6)$. 


\section{ATP Response}
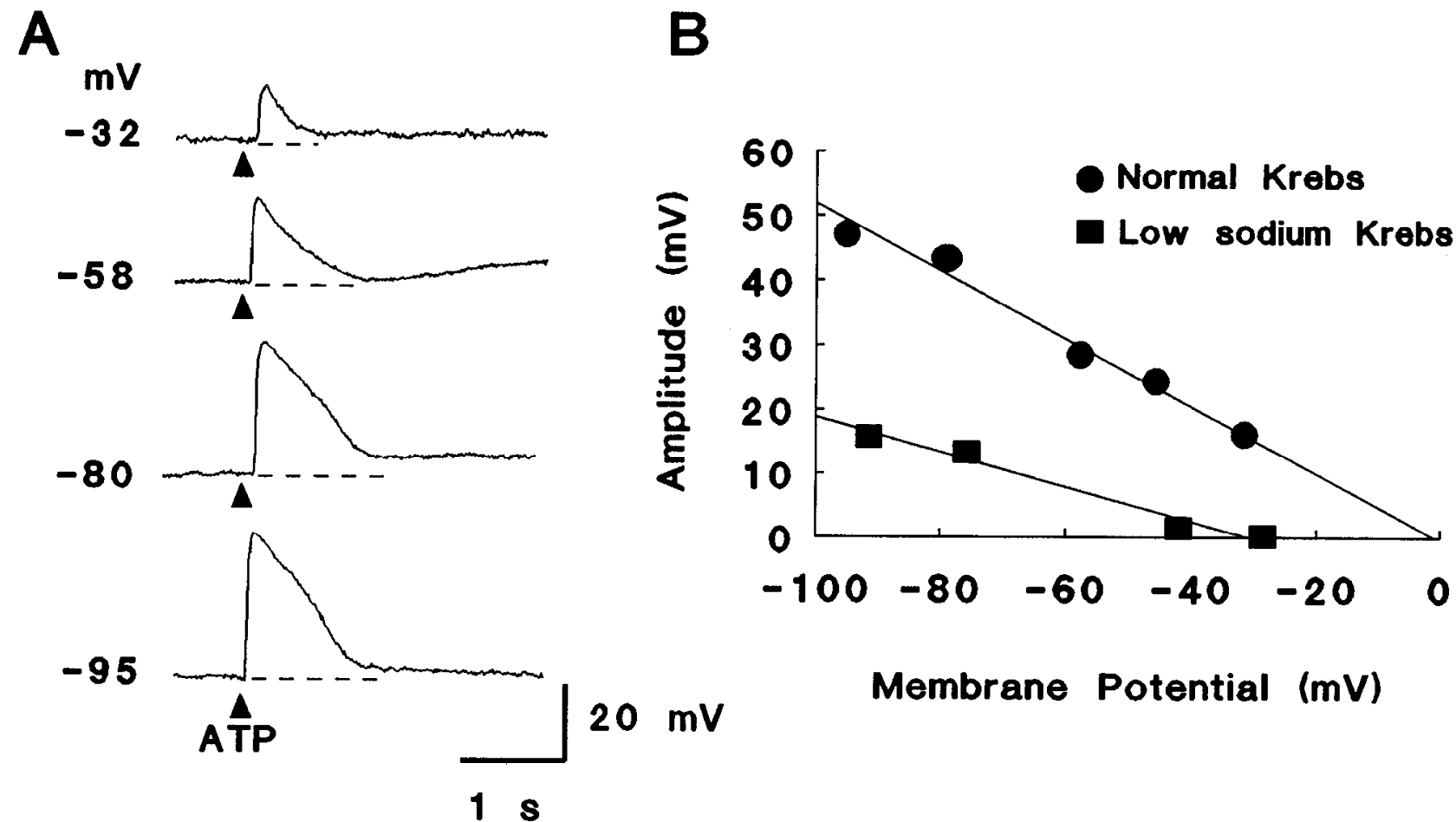

$20 \mathrm{mV}$

\section{Membrane Potential (mV)}

Figure 8. Reversal potential for ATP response. $A$, Amplitude of ATP response at the indicated membrane potentials. $B$, Plot of data shown in $A$. In this cell, the estimated reversal potential was $-2 \mathrm{mV}$. In the same cell, the reversal potential for the ATP response shifted to $-30 \mathrm{mV}$ when the sodium concentration was reduced to $26 \mathrm{~mm}$ (choline chloride substitution for sodium chloride).

\section{Significance of noncholinergic fEPSPS}

ATP induces a depolarization in many neurons in situ and in culture, but the functional significance of the ATP-induced response in these neurons is not clear (Bean, 1992). Recently, it has been shown that when glutamate and GABA receptors are blocked, fast synaptic currents recorded from medial habenula neurons are mediated by ATP.(Edwards et al., 1992). As these studies were done in acutely isolated brain slices, the synaptic responses recorded in these studies are likely to be present in vivo. Celiac ganglion neurons maintained in tissue culture for 1 week or more form autapses which use ATP as the excitatory neurotransmitter (Evans et al., 1992; Silinsky and Gerzanich, 1993). Although occasional ATP-mediated synaptic responses occur in the intact celiac ganglion (Silinsky and Gerzanich, 1993), most fEPSPs in this tissue are blocked by nicotinic antagonists, and the functional significance of ATP-mediated synaptic potentials recorded in tissue culture are unknown (McLachlan and Meckler, 1989; McLachlan and Keast, 1993). We used acutely isolated preparations of myenteric plexus, and most synaptic connections present in the intact intestine would be preserved in this preparation. Therefore, the ATP-mediated fEPSPs recorded here are likely to contribute to ganglionic neurotransmission in intact tissues. Histochemical methods using quinacrine to reveal neuronal stores of ATP have demonstrated that quinacrine-induced fluorescent nerve fibers and nerve cell bodies are found throughout the myenteric plexus of the small intestine of mouse, guinea pig, and rat (Olson et al., 1976). In addition, synaptosomes prepared from the myenteric plexus of guinea pig small intestine release ATP in a calcium-dependent manner (White and Leslie, 1982). These histochemical and neurochemical data are consistent with the electrophysiological data presented here indicating that ATP is a fast synaptic transmitter in the ENS.

Reflex peristaltic contractions can be elicited in vitro in isolatcd scgments of intestine when the lumen of the segment is slowly filled with fluid (Trendelenburg, 1917). The peristaltic reflex involves a filling phase in which the intestinal segment accommodates to the volume of fluid and an emptying phase that occurs when intraluminal pressure has reached a critical level. The emptying phase of the peristaltic reflex is generally blocked by nicotinic antagonists (Furness and Costa, 1987). However, distention-evoked peristalsis in guinea pig ileum can be elicited in the presence of hexamethonium when the tissues are also incubated with the opioid receptor antagonist naloxone (Bartho et al., 1987). Recently, it has been shown that at low rates of distention, the nerve-mediated accommodation that occurs during the filling phase of the peristaltic reflex is not blocked by hexamethonium (Waterman et al., 1994). Both groups concluded that non-nicotinic ganglionic transmission was responsible for the hexamethonium-resistant reflexes they had described. Although previous work dealing with noncholinergic ganglionic transmission in the ENS has focused on slow synaptic transmission (Wood, 1989), it is possible that ATP acting as a fast synaptic transmitter mediates these hexamethonium-resistant reflexes.

In conclusion, ATP-mediated fEPSPs contribute to excitatory ganglionic transmission in the myenteric plexus of guinea pig 
small intestine. It remains to be determined which of the many functionally distinct myenteric nerves release ATP as a neurotransmitter and which neurons receive this excitatory purinergic input. Finally, we have identified noncholinergic fEPSPs that were not blocked by suramin. There are likely to be mediators of fast synaptic transmission in the ENS in addition to ACh and ATP.

\section{References}

Allen TGJ, Burnstock G (1990) The actions of adenosine 5'-triphosphate on guinea-pig intracardiac neurones in culture. Br J Pharmacol 100:269-276.

Ascher P, Large WA, Rang HP (1979) Studies on the mechanism of action of acetylcholine antagonists on rat parasympathetic ganglion cells. J Physiol (Lond) 295:139-170.

Barajas-Lopez C, Barrientos M, Espinosa-Luna R (1993) Suramin increases the efficacy of ATP to activate an inward current in myenteric neurons from guinea pig ileum. Eur J Pharmacol 250:141-145.

Barajas-Lopez C, Espinosa-Luna R, Gerzanich V (1994) ATP closes a potassium and opens a cationic conductance through different receptors in neurons of guinea pig submucous plexus. J Pharmacol Exp Ther 268:1396-1402.

Bartho L, Holzer P, Lembeck F (1987) Is ganglionic transmission through nicotinic receptors essential for the peristaltic reflex in the guinea-pig ileum. Neuropharmacology 26:1663-1666.

Bean BP (1990) ATP-activated channels in rat and bullfrog sensory neurons: concentration dependence and kinetics. J Neurosci 10:1-10.

Bean BP (1992) Pharmacology and electrophysiology of ATP-activated ion channels. Trends Pharmacol Sci 13:87-90.

Bean BP, Williams CA, Ceelen PW (1990) ATP-activated channels in rat and bullfrog sensory neurons: current-voltage relation and single-channel behavior. J Neurosci 10:11-19.

Benham CD, Bolton TB, Byrne NG, Large WA (1987) Action of externally applied adenosine triphosphate on single smooth muscle cells dispersed from rabbit ear artery. J Physiol (Lond) 387:473-488.

Bertrand PP, Galligan JJ (1992) Substance P and ATP activate novel inward currents in myenteric neurons. Pharmacologist 34:158.

Burnstock G, Kennedy C (1985) Is there a basis for distinguishing two types of $P_{2}$ purinoceptor? Gen Pharmacol 16:433-440.

Burnstock G, Kennedy C (1986) A dual function for adenosine 5'triphosphate in the regulation of vascular tone. Circ Res 58:319-330.

Derkach V, Surprenant A, North RA (1989) 5- $\mathrm{HT}_{3}$ receptors are membrane ion channels. Nature 339:706-709.

Dunn PM, Blakely AGH (1988) Suramin: a reversible $P_{2}$-purinoceptor antagonist in the mouse vas deferens. $\mathrm{Br} \mathrm{J}$ Pharmacol 93:243-245.

Edwards FA, Gibb AJ; Colquhoun D (1992) ATP receptor mediated synaptic currents in the central nervous system. Nature 359:144-147.

Evans RJ, Surprenant A (1992) Vasoconstriction of guinea-pig submucosal arterioles following sympathetic nerve stimulation is mediated by the relcase of ATP. Br J Pharmacol 106:242-249.

Evans, RJ, Derkach V, Surprenant A (1992) ATP mediates fast synaptic transmission in mammalian neurons. Nature 357:503-505.

Fieber LA, Adams DJ (1991a) Acetylcholine-evoked currents in cultured neurones dissociated from rat parasympathetic cardiac ganglia. J Physiol (Lond) 434:215-237.

Fieber LA, Adams DJ (1991b) Adenosine triphosphate-evoked currents in cultured neurones dissociated from rat parasympathetic cardiac ganglia. J Physiol (Lond) 434:239-256.

Friel DD (1988) An ATP-sensitive conductance in single smooth muscle cells from the rat vas deferens. J Physiol (Lond) 401:361-380.

Furness JB, Costa M (1987) The enteric nervous system. Edinburgh: Churchill Livingstone.

Hirst GDS, Holman ME, Spence I (1974) Two types of neurones in the mycnteric plexus of the duodenum in the guinea-pig. J Physiol (Lond) 236:303-326.
Hoyle CHV, Knight GE, Burnstock G (1990) Suramin antagonizes responses to $P_{2}$-purinoceptor agonists and purinergic nerve stimulation in guinea pig urinary bladder and taenia coli. Br J Pharmacol 99:617-621.

Jahr CE, Jessell TM (1983) ATP excites a subpopulation of rat dorsal horn neurones. Nature 304:730-733.

Katayama Y, Morita K (1989) Adenosine 5'-triphosphate modulates membrane potassium conductance in guinea-pig myenteric neurones. J Physiol (Lond) 408:373-390.

Krishtal OA, Marchenko SM, Obukhov AG (1988) Cationic channels activated by extracellular ATP in rat sensory neurons. Neuroscience $27: 995-1000$

Langley JN (1921) The autonomic nervous system. Cambridge: Hoeffer.

Mawe G, Branchek TA, Gershon MD (1986) Peripheral neural serotonin receptors: identification and characterization with specific agonists and antagonists. Proc Natl Acad Sci USA 83:9799-9803.

McLachlan EM, Keast JR (1993) Neurotransmitter role for ATP? Nature 361:310.

McLachlan EM, Meckler RL (1989) Characteristics of synaptic input to three classes of sympathetic neurone in the coeliac ganglion of the guinea-pig. J Physiol (Lond) 415:109-129.

Nakazawa K (1994) ATP-activated current and its interaction with acetylcholine-activated current in rat sympathetic neurons. J Neurosci 14:740-750.

Nakazawa K, Inoue K, Fujimori K, Takanaka A (1991a) Effects of ATP antagonists on purinoceptor-operated inward currents in rat phaechromocytoma cells. Pfluegers Arch 418:214-219.

Nakazawa K, Fujimori K, Takanaka A, Inoue K (1991b) Comparison of adenosine triphosphate- and nicotine-activated inward currents in rat phaeochromocytoma cells. J Physiol (Lond) 434:647-660.

Olson L, Alund M, Norberg K-A (1976) Fluorescence-microscopical demonstration of a population of gastro-intestinal nerve fibres with a selective affinity for quinacrine. Cell Tissue Res 171:407-423.

Shen K-Z, North RA (1993) Excitation of rat locus coeruleus neurons by adenosine 5 -triphosphate: ionic mechanism and receptor characterization. J Neurosci 13:894-899.

Silinsky EM, Gerzanich V (1993) On the excitatory effects of ATP and its role as a neurotransmitter in coeliac neurons of the guineapig. J Physiol (Lond) 464:197-212.

Silinsky EM, Gerzanich V, Vanner SM (1992) ATP mediates fast excitatory synaptic transmission in enteric neurones. Br J Pharmacol 106:762-763.

Surprenant A, Crist J (1988) Electrophysiological characterization of functionally distinct 5 -hydroxytryptamine receptors on guinea pig submucous plexus neurones. Neuroscience 24:283-295.

Trendelenburg P (1917) Physiologische und pharmakologische Versuche uber die Dunndarmperistalik. Arch Exp Pathol Pharmakol 81: 51-129.

Ueno S, Harata N, Inoue K, Akaike N (1992) ATP-gated current in dissociated rat nucleus solitarii neurons. J Neurophysiol 68:778-785.

Vanner S, Surprenant A (1990) Effects of 5-HT 3 receptor antagonists on 5-HT and nicotinic depolarizations in guinea pig submucosal neurones. Br J Pharmacol 99:840-844.

von Kugelgen I, Starke K (1991) Noradrenaline-ATP co-transmission in the sympathetic nervous system. Trends Pharmacol Sci 12:319324.

Waterman SA, Costa M, Tonini M (1994) Accommodation mediated by enteric inhibitory reflexes in the isolated guinea pig small intestine. J Physiol 474:539-546.

White TF, Leslie RA (1982) Depolarization-induced release of adenosine 5 -triphosphate from isolated varicosities derived from the myenteric plexus of the guinea pig small intestine. J Neurosci 2:206215.

Wood JD (1989) Electrical and synaptic behavior of enteric neurons. In: I Iandbook of physiology, the gastrointestinal system, Vol 1 (Schultz SG, Wood JD, Rauner BB, eds), pp 465-517. New York: Oxford UP. 